\title{
Improvement of the probiotic effect of micro-organisms by their combination with maltodextrins, fructo-oligosaccharides and polyunsaturated fatty acids
}

\author{
A. Bomba ${ }^{1}$, R. Nemcová ${ }^{1}$, S. Gancarčíková ${ }^{1}$, R. Herich ${ }^{2}$, P. Guba ${ }^{1}$ and D. Mudroňová ${ }^{1}$ \\ ${ }^{1}$ Research Institute of Veterinary Medicine, Hlinkova 1/A, 040 01, Slovak Republic \\ ${ }^{2}$ University of Veterinary Medicine, Komenského 73040 01, Košice, Slovak Republic
}

\begin{abstract}
Probiotics could represent an effective alternative to the use of synthetic substances in nutrition and medicine. The data concerning the efficacy of probiotics are often contradictory. This paper focuses on the enhancement of the efficacy of probiotics by their combination with synergistically acting components of natural origin. Maltodextrins can be obtained by enzymatic hydrolysis of starch and are suitable for consumption. Administration of Lactobacillus paracasei together with maltodextrin decreased the number of Escherichia coli colonising the jejunal mucosa of gnotobiotic piglets by 1 logarithm compared to the control group. Fructo-oligosaccharides (FOS) are naturally occurring oligosaccharides, mainly of plant origin. L. paracasei administered in combination with FOS significantly increased counts of Lactobacillus spp., Bifidobacterium spp., total anaerobes and total aerobes compared to the control group as well as the L. paracasei group. It also significantly decreased Clostridium and Enterobacterium counts in the faeces of the weanling piglets compared with the control group. Dietary lipids influence the gastrointestinal microbiota and specifically the population of lactic acid bacteria. In gnotobiotic piglets the oral administration of an oil containing polyunsaturated fatty acids (PUFA) significantly increased the number of $L$. paracasei adhering to jejunal mucosa compared to the control group. Our results showed that maltodextrin KMS X-70 and PUFA can be used to enhance the effect of probiotic micro-organisms in the small intestine, and similarly FOS enhance the effect of probiotic micro-organisms in the large intestine.
\end{abstract}

Probiotics: Maltodextrin: Fructo-oligosaccharides: Polyunsaturated fatty acids

\section{Introduction}

According to Fuller (1992), probiotics are biopreparations containing living cells or metabolites of stabilised autochthonous micro-organisms that optimise the colonisation and composition of the gut microflora in both animals and humans and stimulate digestive processes and immunity. For practical purposes it is important that probiotics have effects, such as an inhibitory effect against pathogens, an optimising effect on digestive processes, an immunostimulatory effect, anti-tumour effect and anticholesterol action.

The mode of action of probiotics has not been fully explained. The mode of inhibitory action of probiotics against pathogens may be mediated by competition for receptors on the gut mucosa, competition for nutrients, the production of antibacterial substances, and the stimulation of immunity (Piard \& Desmazeaud, 1991; Freter, 1992;
Perdigon \& Alvarez, 1992). Probiotics influence digestive processes by enhancing the population of beneficial microorganisms, by enhancing microbial enzyme activity and by improving digestibility of foodstuffs and feed utilisation (Burgstaller et al. 1984). Optimisation of digestive processes is demonstrated by improved growth and higher weight gains. The anti-tumour activity of probiotics may be realised in three ways: the inhibition of tumour cells; the suppression of bacteria producing beta-glucosidase, beta-glucuronidase, and azoreductase, which catalyse the conversion of procarcinogens to proximal carcinogens; and by the destruction of carcinogens such as nitrosamines and by the suppression of nitroreductase which is involved in their synthesis (Reddy et al. 1973; Rowland \& Grasso, 1975; Goldin \& Gorbach, 1977, 1984). Probiotics influence blood cholesterol level by the inhibition of cholesterol synthesis or by decreasing absorption (Mann, 1977; Zacconi et al. 1992). 


\section{Enhancing the efficacy of probiotics}

Probiotics as natural bio-regulators help to maintain the balance of the digestive tract ecosystem by a variety of mechanisms and prevent the colonisation of the digestive tract by pathogenic bacteria (Vandenbergh, 1993). In agriculture and veterinary medicine, probiotics may be effectively used particularly in optimising digestive processes, growth stimulation, and in the prevention of digestive tract diseases in young farm animals. The data concerning the efficacy of probiotics in practice are often contradictory. With regard to the application of probiotic lactobacilli to pigs, many authors have reported a growth and stimulatory effect (Baird, 1977; Hale \& Newton, 1979; Pollmann et al. 1980; Nousiainen \& Setälä, 1993). However, some authors did not observe growth improvement with the administration of probiotics. The data concerning the efficacy of probiotics in the prevention of diarrhoeal diseases in young animals are also contradictory. The effect of lactobacilli and bifidobacteria against diarrhoea in pigs was confirmed by several reports (Hale \& Newton 1979; Kimura et al. 1983; Maeng et al. 1989; Depta et al. 1998; Bomba et al. 1998). However, other authors (De Cupere et al. 1992; Bekaert et al. 1996) have not confirmed this effect.

The efficacy of probiotics under different conditions may be due to the probiotic preparation itself or may be caused by other factors. Variability of the data may be due to: low survival rate of strains, stability of the strain, the use of a non-specific strain relative to the host, low dose and frequency of administration, interactions with some medicines, health and nutritional status of the animal and the effect of age, stress, genetics and type differences of animals. Research experience points to the fact that probiotics are most effective in animals during microflora development or when microflora stability is impaired (Stavric \& Kornegay, 1995). A probiotic strain should be non-pathogenic and be able to tolerate the conditions of the digestive tract and adhere in high numbers to the digestive tract mucosa; it should be able to maintain high viability during processing, lyophilisation, and storage, re-vitalise quickly in the digestive tract; it should be able to produce inhibitory substances against pathogens and stimulate the immune system (Chesson, 1993). Some of the above-mentioned criteria for the selection of microorganisms for probiotic purposes can be tested in vitro, but most of them must be verified in vivo. Some properties of micro-organisms observed under laboratory conditions have not been confirmed in trials with animals (Chateau et al. 1993; Bomba et al. 1996).

In order to enhance the efficacy of probiotics, it is necessary to obtain important knowledge of the mechanisms mediating their effect in the digestive tract (Stavric \& Korgenay, 1995). The anti-bacterial effect of each probiotic micro-organism or its beneficial effect on the macroorganism may be mediated by one or a number of mechanisms that may be expressed at different degrees of intensity. This indicates that it is necessary to study thoroughly the mode of action of each probiotic microorganism so that the multi-factorial nature of the mechanism can be explained. The efficacy of probiotics may be enhanced by the following methods:

- the selection of more efficient strains of micro-organism

- genetic manipulation

- the combination of a number of probiotic strains

- the combination of probiotics and synergistically acting components.

The combination of probiotics with synergistically acting components of natural origin seems to be a way of enhancing the efficacy of probiotic preparations from the practical point of view. It seems that a number of suitable components may be used to potentiate the effect of probiotics, such as oligosaccharides, phyto-components, nutrients and growth factors, proteins, polyunsaturated fatty acids (PUFA), organic acids and bacterial metabolites (Pollmann et al. 1980; Gálfi \& Bokori, 1990; Gibson \& Roberfroid, 1995; Yadava et al. 1995).

\section{Probiotics and maltodextrins}

We have found that under in vitro conditions Lactobacillus paracasei utilised KMS X-70 maltodextrins. However, the pathogenic Escherichia coli 08: K88 grew poorly in its presence. L. paracasei inhibited the growth of pathogenic $E$. coli 08: K88 strain in the presence of KMS X-70 maltodextrin. These results suggest that under in vitro conditions, KMS X-70 maltodextrin may induce the growth of $L$. paracasei as well as the colonisation of the digestive tract under in vivo conditions.

We investigated the influence of administration of $L$. paracasei and maltodextrin KMS X-70 (JEP CEREPA, Červená Řečice, Czech Republic) on E. coli adhesion in the gastrointestinal tract of gnotobiotic piglets. The administration of $L$. paracasei alone had no inhibitory effect on the adhesion of $E$. coli to the jejunal mucosa of gnotobiotic piglets while $L$. paracasei administered together with maltodextrin decreased the number of $E$. coli colonising the jejunal mucosa of gnotobiotic piglets by 1 logarithm $\left(4.95 \log 10 / \mathrm{cm}^{2}\right)$ in comparison to the control group $\left(5.96 \log 10 / \mathrm{cm}^{2}\right.$, Fig. 1). Maltodextrin KMS X-70 stimulated the inhibitory effect of $L$. paracasei on the adhesion of $E$. coli to the jejunal mucosa of gnotobiotic piglets.

\section{Probiotics and fructo-oligosaccharides}

Fructo-oligosaccharides (FOS) are naturally occurring oligosaccharides, mainly of plant origin. They have been shown to be resistant to endogenous glycolytic enzymes of the host and to pass unaltered to the colon (Oku et al. 1984). FOS can significantly modulate the colonic microbiota by increasing the number of specific bacteria and thus changing the composition of the microbiota.

The concept of synbiotics (a mixture of probiotics and oligosaccharides) has recently been proposed to characterise health-enhancing foods and supplements used as functional food ingredients in humans (Gibson \& Roberfroid, 1995; Kontula et al. 1998). With a combination of both a probiotic and an oligosaccharide, the benefits include improved survival of the probiotic bacteria during passage through the upper intestinal tract and a more efficient 


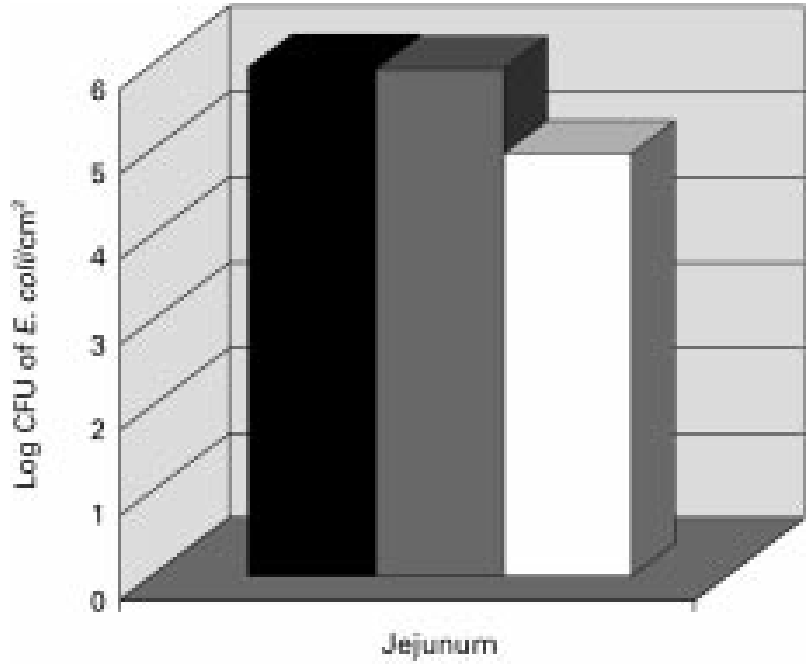

Fig. 1. The numbers of Escherichia coli 08: K88 adhering to the jejunal mucosa in 7-day-old gnotobiotic pigs after administration of Lactobacillus paracasei and maltodextrin KMS X-70. (匹), E. coli 08: K88; $(\square)$, L. paracasei + E. coli 08: K88; $(\square)$, L. paracasei+ maltodextrin KMS X-70 + E. coli 08: K88.

implantation in the colonic microbiota, together with a stimulating effect of the oligosaccharide on the growth and/or activities of both the exogenous (probiotic) and endogenous bacteria (Roberfroid, 1998).

We examined the effect of the administration of $L$. paracase $i$ and a mixture of L. paracase $i$ and FOS on faecal bacterial counts of weanling pigs under field conditions.

Numbers of individual bacterial populations found in both experimental and control animals are presented in Table 1. Significantly higher counts of Lactobacillus spp. $(P<0 \cdot 01)$, Bifidobacterium spp. $(P<0 \cdot 05)$, total anaerobes $(P<0.05)$ and total aerobes $(P<0.05)$ were found in faeces of experimental animals receiving the mixture of $L$. paracasei and FOS (Raftilose P95, Raffinerie Tirlemontoise, Tienen, Belgium) compared with the controls. Moreover, significantly higher numbers of anaerobes $(P<0 \cdot 05)$, total aerobes $(P<0.05)$, Bifidobacterium $(P<0.05)$ and Lactobacillus $(P<0.05)$ counts were found compared to the $L$. paracasei group. Compared to the controls, significant decreases in Clostridium $(P<0.05)$ and Enterobacterium $(P<0 \cdot 01)$ counts were also observed as well as an insignificant decrease in coliform counts. In addition, Enterococcus counts were significantly reduced $(P<0 \cdot 001)$ compared to both the control group and the $L$. paracasei group. In faeces of experimental animals receiving $L$. paracasei, significant decreases in Clostridium $(P<0.05)$ and Enterobacterium $(P<0.05)$ counts as compared with the controls were recorded. Coliform counts were lower by $0.5 \mathrm{log}$ compared with controls. This difference, however, was not significant due to the great individual variability in the data. Lactobacillus, Enterococcus and total anaerobes counts were identical in both groups. A non-significant increase in total aerobes in the experimental group was recorded and there was a non-significant decrease in Bifidobacterium spp. as compared to the control group. The results of this study point to a synergistic effect of the L. paracasei and FOS combination on faecal microflora of weaned pigs.

\section{Probiotic and polyunsaturated fatty acids}

Competition for receptors on the gut mucosa is one mechanism of inhibitory action of probiotics against pathogens in the digestive tract of animals (Stavric et al. 1987). Improvement in the colonisation of the intestinal mucosa by probiotic bacteria enhances the inhibitory effect of probiotics upon the adhesion of pathogens. It was demonstrated that dietary lipid influences the gastrointestinal microbiota and especially the population level of lactic acid bacteria (Ringo et al. 1998). According to Kankaanpää et al. (2001), higher concentrations of PUFA inhibited the growth and mucus adhesion of selected lactobacilli, whilst growth and mucus adhesion of Lactobacillus casei Shirota was promoted by low concentrations of $\gamma$-linolenic acid and arachidonic acid, respectively. PUFA also altered bacterial adhesion sites on Caco- 2 cells. It is suggested that dietary PUFA affects the attachment sites for the gastrointestinal microbiota, possibly by modifying the fatty acid composition of the intestinal wall.

We studied the effect of administration of PUFA on the

Table 1. Composition of faecal microflora in weanling pigs receiving Lactobacillus paracasei and mixture of $L$. paracasei and fructo-oligosaccharides (FOS)

(Mean values with their standard errors of log bacteria counts per gram of wet faeces for seven determinations)

\begin{tabular}{|c|c|c|c|c|c|c|}
\hline \multirow[b]{2}{*}{ Organism } & \multicolumn{2}{|c|}{ Control } & \multicolumn{2}{|c|}{ L paracasei } & \multicolumn{2}{|c|}{ L. paracasei + FOS } \\
\hline & Mean & SE & Mean & SE & Mean & SE \\
\hline Total anaerobes & 9.8 & 0.2 & $9 \cdot 8$ & 0.3 & $10 \cdot 2$ & $0.2 \dagger^{\star}, \ddagger^{*}$ \\
\hline Total aerobes & 8.0 & 0.5 & 8.3 & 0.2 & $9 \cdot 3$ & $0.7 \dagger^{*}, \ddagger^{*}$ \\
\hline Bifidobacterium spp. & 7.5 & 0.3 & $7 \cdot 1$ & 0.7 & 8.2 & $0.3 \dagger^{*}, \ddagger^{*}$ \\
\hline Lactobacillus spp. & 9.9 & 0.1 & 9.9 & 0.3 & $10 \cdot 3$ & $0.1 t^{\star \star}, \ddagger^{*}$ \\
\hline Enterococcus spp. & $9 \cdot 3$ & 0.1 & $9 \cdot 3$ & 0.3 & 8.2 & $0.2 十^{\star \star \star}, \ddagger^{\star \star \star}$ \\
\hline Clostridium spp. & 8.1 & 0.1 & 7.4 & $0.4 \dagger^{\star}$ & $7 \cdot \overline{7}$ & $0.3 t^{*}$ \\
\hline Enterobacteriaceae & 7.9 & 0.4 & $6 \cdot 5$ & $0.9 \dagger^{*}$ & 5.9 & $0.9 \dagger^{* *}$ \\
\hline Coliforms & $6 \cdot 8$ & 0.7 & $6 \cdot 3$ & 0.7 & $5 \cdot 8$ & 0.7 \\
\hline
\end{tabular}

†Significantly different from control group.

$¥$ Significantly different from $L$. paracasei group.

${ }^{*} P<0.05 ;{ }^{* \star} P<0.01 ;{ }^{* * *} P<0.001$ 


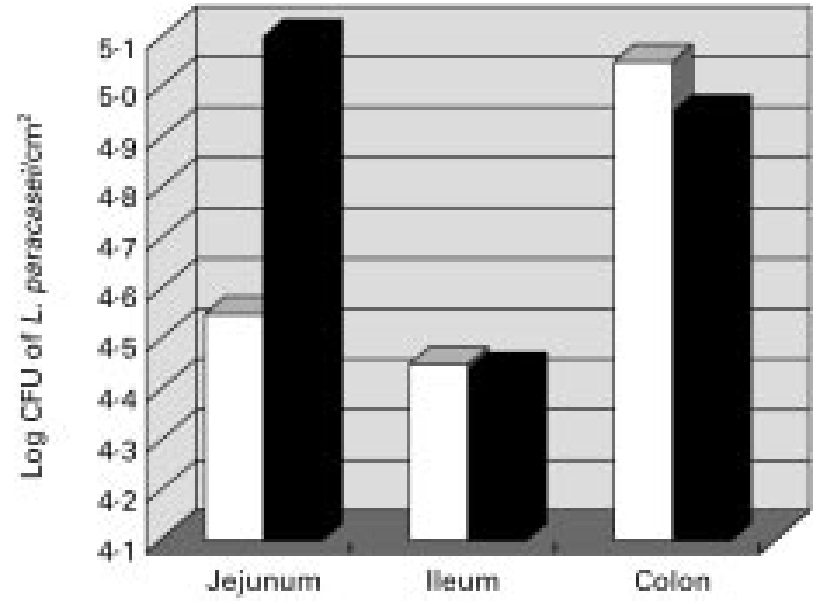

Fig. 2. Lactobacillus paracasei colonisation of the jejunal, ileal and colonic mucosa of gnotobiotic piglets after administration of polyunsaturated fatty acids (PUFA) or $\mathrm{NaCl}$. ( $\square$ ), L. paracasei $+0.7 \%$ $\mathrm{NaCl} ;(\mathbf{\square})$, L. paracasei + PUFA.

adhesion of $L$. paracase $i$ to the intestinal mucosa in the gnotobiotic piglets. The number of $L$. paracasei adhering to jejunal mucosa in the gnotobiotic piglets orally administered an oil blend (Seal oil, Star Enterprises, Saint John, Newfoundland, Canada) containing $0.1 \mathrm{~g}$ total $n-6$ PUFA, $1.0 \mathrm{~g}$ total $n-3$ PUFA, $2.6 \mathrm{~g}$ total monounsaturated fatty acids, $0.9 \mathrm{~g}$ total saturated fatty acids and $0.005 \mathrm{~g}$ cholesterol was significantly higher $\left(P<0 \cdot 05,5 \cdot 10 \log 10 / \mathrm{cm}^{2}\right)$ in comparison with the control group $\left(4.55 \mathrm{log} 10 / \mathrm{cm}^{2}\right.$; Fig. 2). Administration of the PUFA affected the adhesion of $L$. paracasei to the jejunal mucosa of gnotobiotic piglets. The stimulatory effect of PUFA upon adhesion of lactobacilli could be used for enhancing the effectiveness of probiotics in inhibiting digestive tract pathogens.

\section{Conclusions}

Future research should be aimed at the selection of strains with strong probiotic effects, which will comply with specific criteria of selection. It will be important to search for ways to potentiate the efficacy of probiotic micro-organisms in all regions of the digestive tract. In addition to prebiotics, which potentiate the effect of probiotics in the colon, there should be components that, in combination with probiotic preparations, will ensure their efficacy in the small intestine also. Our results showed that maltodextrin KMS X-70 and PUFA can be used for potentiating the probiotic effect in the small intestine, and FOS can be used for potentiating the probiotic effect in the large intestine. It has been suggested that their combination may result in potentiation of the probiotic effect in all sections of the digestive tract but this hypothesis needs further research.

\section{References}

Baird DM (1977) Probiotics help boost feed efficiency. Feedstuffs 49, 11.

Bekaert H, Moermans R \& Eeckhout W (1996) Influence d'une culture de levure vivante (Levucell SB2) dans un aliment pour porcelets sevrés sur les performances zootechniques et sur la fréquence des diarrhées (Influence of the live culture of yeasts in feed on the performance and incidence of diarrhea in piglets). Annales de Zootechnie 45, 369-376.

Bomba A, Gancarčíková S, Nemcová R, Herich R, Kaštel' R, Depta A, Demeterová M, Ledecký V \& Žitňan R (1998) The effect of lactic acid bacteria on intestinal metabolism and metabolic profile of gnotobiotic pigs. Deutsche Tierärztliche Wochenschrift 105, 384-389.

Bomba A, Kaštel' R, Gancarčíková S, Nemcová R, Herich R \& Č́žek M (1996) The effect of Lactobacilli inoculation on organic acid levels in the mucosal film and the small intestine contents in gnotobiotic pigs. Berliner und Münchener Tierärztliche Wochenschrift 109, 428-430.

Burgstaller G, Ferstl R \& Apls H (1984) Zum Zusatz von Milchsäurebakterien (Streptococcus faecium SF-68) im Milchaustauschfuttermittel fur Mastkälber (The addition of lactic acid bacteria to a milk replacer for calf feeding). Zuchtungskunde 56, $156-162$.

Chateau N, Castellanos I \& Deschamps AM (1993) Distribution of pathogen inhibition in the Lactobacillus isolates of a commercial probiotic consortium. Journal of Applied Bacteriology 74, 36-40.

Chesson A (1993) Probiotics and other intestinal mediators. In Principles of Pig Science, pp. 197-214 [DJA Cole, J-MA Wisiman and MA Varley, editors]. Loughborough: Nottingham University Press.

De Cupere F, Deprez P, Demeulenaere D \& Muylle E (1992) Evaluation of the effect of 3 probiotics on experimental Escherichia coli enterotoxaemia in weaned piglets. Journal of Veterinary Medicine B 39, 277-284.

Depta A, Rychlik R, Nieradka R, Rotkiewicz T, Kujawa K, Bomba A \& Grabowska-Świecicka G (1998) The influence of alimentary tract colonization with Lactobacillus sp. strains on chosen metabolic profile indices in piglets. Polish Journal of Veterinary Science 1-2, 3-7.

Freter R (1992) Factors affecting the microecology of the gut. In Probiotics: The Scientific Basis, pp. 111-114 [R Fuller, editor]. London: Chapman and Hall.

Fuller R (1992) The effect of probiotics on the gut microbiology of farm animals. In The Lactic Acid Bacteria, pp. 171-192 [BJB Wood, editor]. London: Elsevier Applied Science.

Gálfi P \& Bokori J (1990) Feeding trial in pigs with a diet containing sodium n-butyrate. Acta Veterinaria Hungarica 38, $3-17$.

Gibson GR \& Roberfroid MB (1995) Dietary modulation of the human colonic microbiota: introducing the concept of prebiotics. Journal of Nutrition 125, 1401-1412.

Goldin BR \& Gorbach SL (1977) Alterations in fecal microflora enzymes related to diet, age, lactobacillus supplements and dimethylhydrazine. Cancer 40, 2421-2426.

Goldin BR \& Gorbach SL (1984) The effect of milk and lactobacillus feeding on human intestinal bacterial enzyme activity. American Journal of Clinical Nutrition 39, 756-761.

Hale OM \& Newton GL (1979) Effects of a non-viable lactobacillus species fermentation product on performance of pigs. Journal of Animal Science 48, 770-775.

Kankaanpää PE, Salminen SJ, Isolauri E \& Lee YK (2001) The influence of polyunsaturated fatty acids on probiotic growth and adhesion. FEMS Microbiology Letters 194, 149-153.

Kimura N, Yoshikane M, Kobayashi A \& Mitsuoka T (1983) An application of dried bifidobacteria preparation to scouring animals. Bifidobacteria and Microflora 2, 41-55.

Kontula P, Jaskari J, Nollet L, De Smet I, von Wright A, Poutanen K \& Mattila-Sandholm T (1998) The colonization of a stimulator of the human intestinal microbial ecosystem by a probiotic 
strain fed on a fermented oat bran product: effects on the gastrointestinal microbiota. Applied Microbiology and Biotechnology 50, 246-252.

Maeng WJ, Kim CW \& Shin HT (1989) Effect of feeding lactic acid bacteria concentrate (LBC, Streptococcus faecium Cernelle 68) on the growth rate and prevention of scouring in piglets. Korean Journal of Animal Science 31, 318.

Mann GV (1977) A factor of yoghurt which lowers cholesterolaemia in man. Atherosclerosis 26, 335-340.

Nousiainen J \& Setälä J (1993) Lactic acid bacteria as animal probiotics. In Lactic Acid Bacteria, pp. 315-356 [S Salminen and A von Wright, editors]. New York: Marcel Dekker.

Oku T, Tokunaga T \& Hosoga N (1984) Nondigestibility of a new sweetener 'Neosugar' in the rat. Journal of Nutrition 114, 1574-1581.

Perdigón G \& Alvarez S (1992) Bacterial interactions in the gut. In Probiotics. The Scientific Basis, pp. 145-180 [R Fuller, editor]. London: Chapman and Hall.

Piard JC \& Desmazeaud M (1991) Inhibiting factors produced by lactic acid bacteria. 1. Oxygen metabolites and catabolism endproducts. Lait 71, 525-541.

Pollmann DS, Danielson DM, Wren WB, Peo ER \& Shahani KM (1980) Influence of Lactobacillus acidophilus inoculum on gnotobiotic and conventional pigs. Journal of Animal Science 51, 629-637.

Reddy GV, Shahani KM \& Banerjee MR (1973) Inhibitory effect of the yogurt on Ehrlich ascites tumor cell proliferation. Journal of National Cancer Institute 50, 815-817.
Ringo E, Bendiksen HR, Gausen SJ, Sundsfjord A \& Olsen RE (1998) The effect of dietary fatty acids on lactic acid bacteria associated with the epithelial mucosa and from faecalia of Arctic charr, Salvelinus alpinus (L.). Journal of Applied Microbiology 85, 855-864.

Roberfroid MB (1998) Prebiotics and synbiotics: concepts and nutritional properties. British Journal of Nutrition 80, Suppl. 2, S197-S202.

Rowland IR \& Grasso P (1975) Degradation of $N$-nitrosamines by intestinal bacteria. Applied Microbiology 29, 7-12.

Stavric S, Gleeson TM, Blanchfield B \& Pivnick H (1987) Role of adhering microflora in competitive exclusion of Salmonella from young chicks. Journal of Food Protection 50, 928-932.

Stavric S \& Kornegay ET (1995) Microbial probiotic for pigs and poultry. In Biotechnology in Animal Feeds and Animal Feeding, pp. 205-231 [RJ Wallace and A Chesson, editors]. Weinheim: VCH Verlagsgesellschaft $\mathrm{mbH}$.

Vandenbergh PA (1993) Lactic acid bacteria, their metabolic products and interference with microbial growth. FEMS Microbiology Review 12, 221-238.

Yadava JNS, Gupta S, Ahmad I, Varma N \& Tandon JS (1995) Neutralization of enterotoxins of E. coli by coleonol (forskolin) in rabbit and guinea pig ileal loop models. Indian Journal of Animal Science 65, 1177-1181.

Zacconi C, Bottazzi V, Rebecchi A, Bosi E, Sarra PG \& Tagliaferi L (1992) Serum cholesterol levels in axenic mice colonized with Enterococcus faecium and Lactobacillus acidophilus. Microbiologica 15, 413-418. 